\title{
Design-Based Research: Students seeking co-op in new educational model
}

\author{
Dr. Dennis Rogalsky, Minnesota State University, Mankato \\ Dr. Bart M Johnson, Itasca Community College
}

Bart Johnson is the Provost of Itasca Community College. He is active in engineering education research and is a former engineering instructor and program coordinator at Itasca. Dr. Johnson is a co-founder of the ABET Innovation Award recognized Iron Range Engineering program. Prior to Itasca, he was a design engineer in John Deere's Construction and Forestry Division.

\section{Dr. Ronald R Ulseth, Iron Range Engineering}

Ron Ulseth directs and instructs in the Iron Range Engineering program in Virginia, Minnesota and he teaches in the Itasca Community College engineering program in Grand Rapids, MN. He was instrumental in growing the Itasca program from 10 students in 1992 to 160 students in 2010. In 2009, he worked with a national development team of engineering educators to develop the 100\% PBL curriculum used in the Iron Range model. He has successfully acquired and managed over $\$ 10$ million in educational grants including as PI on 7 grants from NSF. He has been in the classroom, teaching more than 20 credits per year to engineering students for more than 30 years. His specific areas of expertise are in active learning, faculty development, and learning community development. He has been awarded the 2012 Progress Minnesota award, 2012 Labovitz Entrepreneurialism award, and 2012 Innovator of the Year award from the Rural Community College Alliance all for his work in developing the Iron Range Engineering program. His degrees are in civil engineering (B.S., University of North Dakota), mechanical engineering (M.S., University of Central Florida), and engineering education (Ph.D., Aalborg University). He is licensed as a professional engineer in the state of Minnesota. 


\title{
Design-Based Research: Students seeking co-op in new educational model
}

\begin{abstract}
This research paper continues a longitudinal implementation of a design-based research (DBR) study and implementation for a new co-op centric educational model. This is a benchmarking study by the university program. Two iterative cycles take place simultaneously in the DBR study and interface to provide knowledge to one another. One cycle is the design of a new program, the other cycle is the research study. In this study, the research cycle includes literature review, data acquisition, analysis, evaluation, and findings. Out of the findings come recommendations for continuous improvement in the program design.
\end{abstract}

In this paper, the new model as well as the research method are described. The data analysis results in findings for the program regarding student attainment of the co-op. It identifies that the too much training and emphasis was put on students submitting a high quantity of "cold-call" applications. Instead, the data shows that students actually acquired their positions through career-fairs and networking. More findings are presented and future steps for both the program design and the research study are recommended. The findings of the research will feed back into the program for the second cohort of 50 students which starts in August 2020.

\section{Design-Based Research Method}

The curricular development work for this PBL program began in 2016 [1] utilizing design-based research (DBR) as the methodology for both design and research. Design-based research (DBR) was adopted as the methodology to 1) address learning theories, 2) to study learning in context, 3 ) to develop measures of learning, and 4) to contribute to new designs and learning theories [2] for the program development. The work incorporates the four phases of DBR identified by Kolmos [3]: design; implementation; data collection and analysis; and findings and conclusions. The DBR phases were adapted and combined with Andriessen's [4] dual purpose of DBR model as illustrated in Figure 1. The focus of the program design is progressive refinement through the problem statement; defining the design and learning objectives; planning (project management) of the curricular design, development of the curricular ideation and selection of a design for initial implementation; and ultimately a continuously reformed model with a curricular model improvement process. The focus of the research design is to establish the research questions; identify the learning theories applicable to the research work; design of the research work that influences the curricular implementation and improvement; and ultimately to disseminate what is learned and add to the body of knowledge on engineering education. 


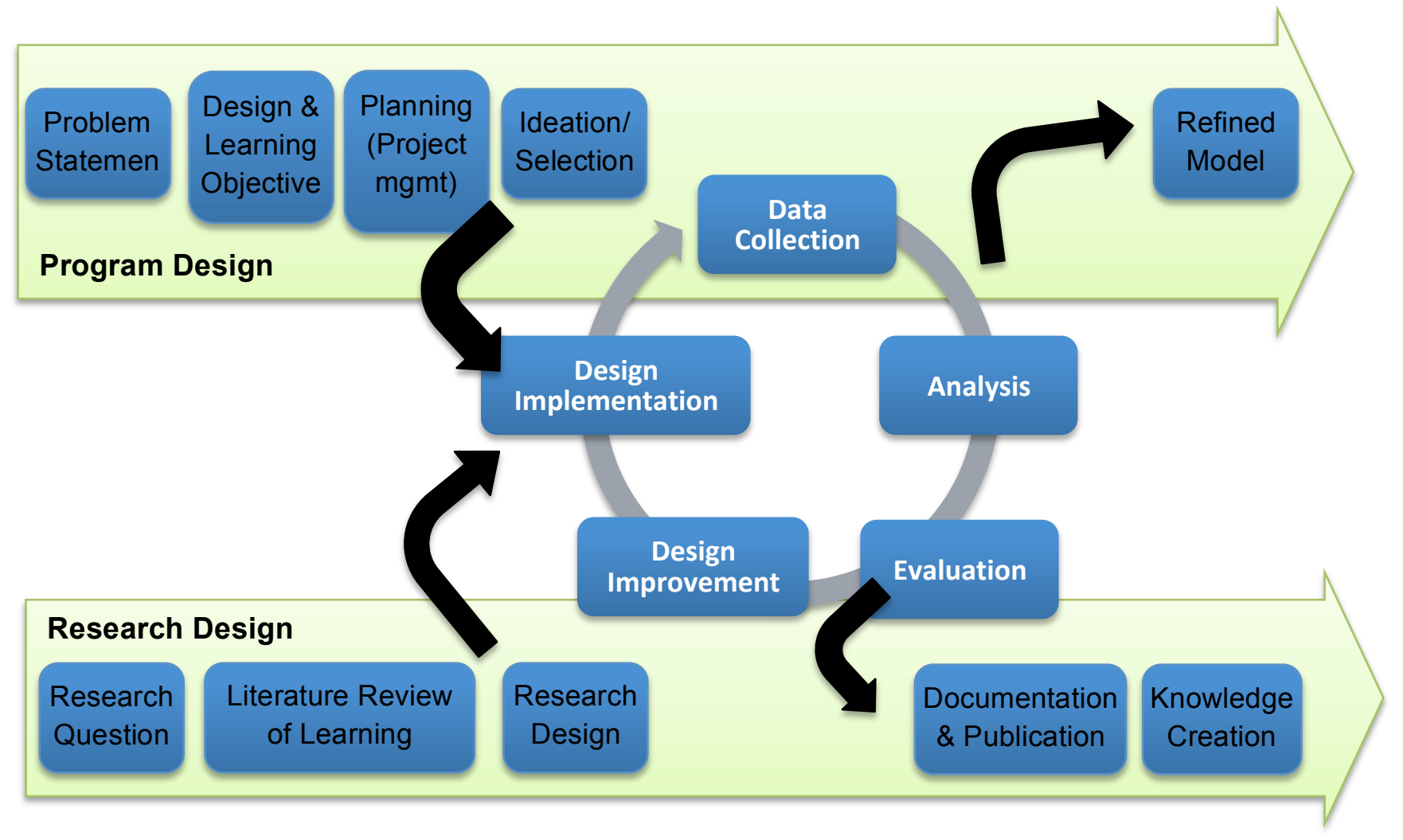

Figure 1. Adapted DBR Process Cycle

Previous iterations were focused on how the curricular element would be developed [1] and how students and faculty members viewed the new curriculum [5]. This paper will look at how students experienced the attainment of their first co-op placement. The research question for this phase of the program development is: "How do BELL program student engineers experience the attainment of their first co-op placement?" In the data collection section below, the student experiences and inputs have been collected and analyzed. Improvements have been put in place and ideas are available to draw on for future iterations.

\section{Model Description}

This new co-op centric educational model is an adaptation of two emerging world-leading engineering educational models, as recognized by a 2018 MIT report [6], Charles Sturt University (Australia) and Iron Range Engineering (Minnesota). Adapted from Charles Sturt is the co-op model whereby students spend an initial on-campus period and then combine co-op work placements and on-line learning all the way to degree completion [7]. Adapted from Iron Range are the curricular strategies that empower a graduate with a balanced technical, professional, and design set of capabilities [8]. In this new model, students complete their lower- 
division pre-engineering requirements at a community college anywhere in the U.S., then transfer into the model for a one-semester intensive on-ground experience, the engineering development phase (EDP), where they acquire the self-directed learning and professional skills needed to thrive in a co-op placement. Upon completion of the engineering development phase (EDP), students enter 24 months of co-op placement/on-line learning, returning to the institution after 12 months and 24 months for one-week examination periods (See Figure 2.).

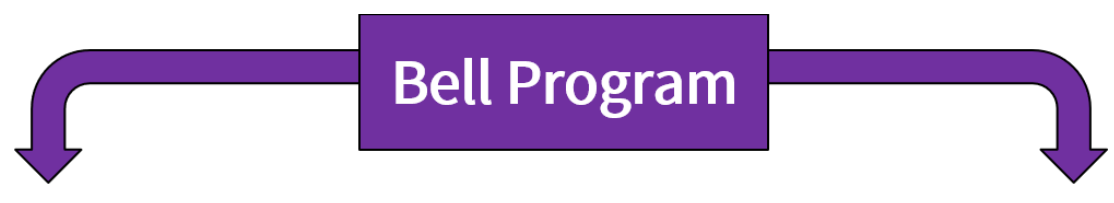

\section{Supported in technical learning by professors}

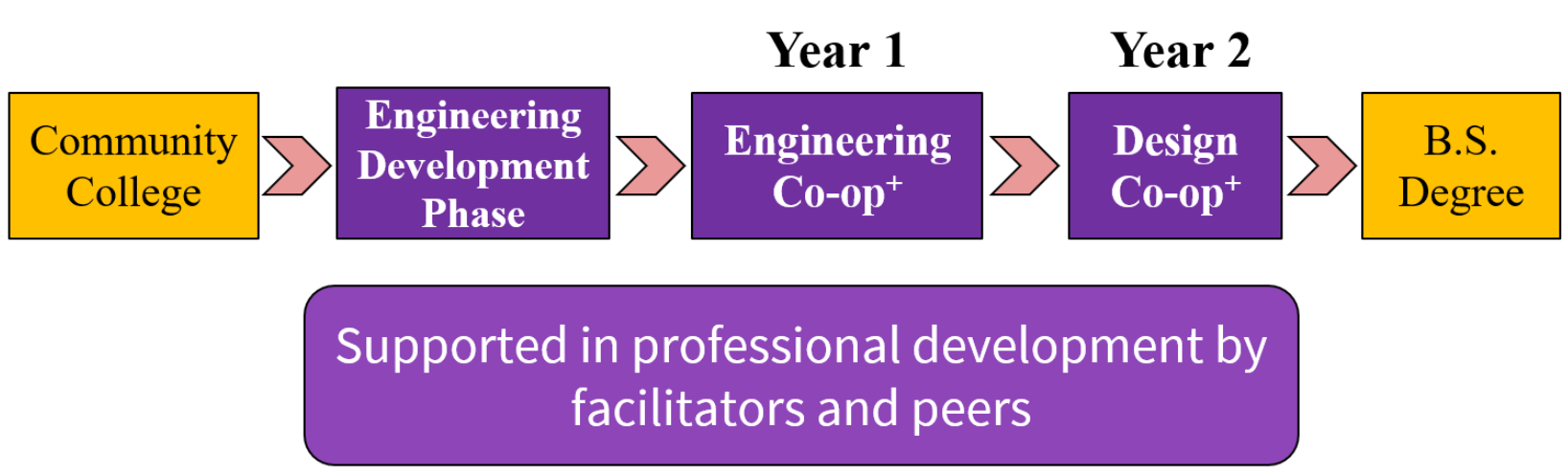

Figure 2. Co-op Program Model

The motivations to start the new program come from a desire to move towards work-based learning, empowering student engineers to gain more practical experience while funding a larger percentage of their own education than through a traditional engineering education. The evolution of learning technologies empowers the attainment of this goal more so today than in the recent past. A further motivation is developing a model that can potentially impact the lack of diversity in the engineering profession. The demographic of community college students is considerably more diverse than the engineering profession [9] and the new program makes an engineering education more accessible to community college students.

Cohort 1 entered the engineering development phase (EDP) in August 2019, completing it in December. Cohort 2 will begin in August 2020 and Cohort 3 in January 2021. There are many aspects to describing the model; relevant aspects to this research paper are described in the following sections. 


\section{Engineering Development Phase}

The engineering development phase (EDP) is an intensive on-site experience focused on the development of the individual in four domains: design, technical, professional, and job-search.

Design learning happens with an engineering project from an industrial client, serving as the central component to the student experience, as is done in the Aalborg University (Denmark) model of project-based learning (PBL) [10]. Students undertake four, one-month project design "sprint" cycles. During these "sprint" cycles, they practice an iterative engineering design process progressing from problem definition through scoping, research, ideation, modeling, testing, and design evaluation; all while making several verbal presentations and going through several iterations of written technical documents. To promulgate multiple teaming experiences, individual members left their design team for one cycle to join a new group undertaking a completely different design with a different client, returning to their original team and finishing their original project.

Technical learning happens in the Iron Range Engineering model whereby students complete 32 one-credit courses (16 core, 16 advanced elective) [11] across the whole program. Eight of these courses take place during the EDP with students taking two courses per block across four onemonth blocks. To provide a scaffolded experience for the students, the first block courses are similar to the traditional model of learning that students have experienced. In each successive block, scaffolding is removed as they transition towards being self-directed managers of their own learning by taking on more responsibility in the learning process. Students write learning plans; develop questioning techniques; accumulate knowledge with an eye towards long-term reflection; apply engineering principles to multiple open-ended problems; and use reflection and metacognition as ways to promote technical knowledge transfer [12].

Professional learning happens across multiple domains. Professional responsibility is modeled and practiced throughout as timeliness, respect, appropriate dress, appropriate language are all made explicit with continuous feedback coming from faculty and staff. Teamwork skills are provided in seminars and practiced in design teams. Multiple workshops per week address topics such as: inclusion, ethical action, leadership, reflection, management, happiness, life-work balance, overcoming adversity, and communication. Each week during the EDP students write three one-page learning journal entries, most of which are reflective prompts from some aspect of professional learning. These student reflections related to professional capabilities continue throughout the program.

Job-search learning happens through several cycles of the "jobs package". In the jobs package, students prepare a cover-letter and resume for a posting they plan to apply to. Two faculty members give them developmental feedback on their submissions. Students then undergo a mock phone interview for the position, receiving feedback on their performance. The next step is an in- 
person live interview. Here students are interviewed by a panel of faculty and other students. Thus, they not only receive performance feedback but can learn from the successes and failures of others and the process of giving feedback. Finally, students send thank you communications and receive feedback on the substance and form of this communication. A graphical depiction of the jobs package elements is shown in Figure 3.

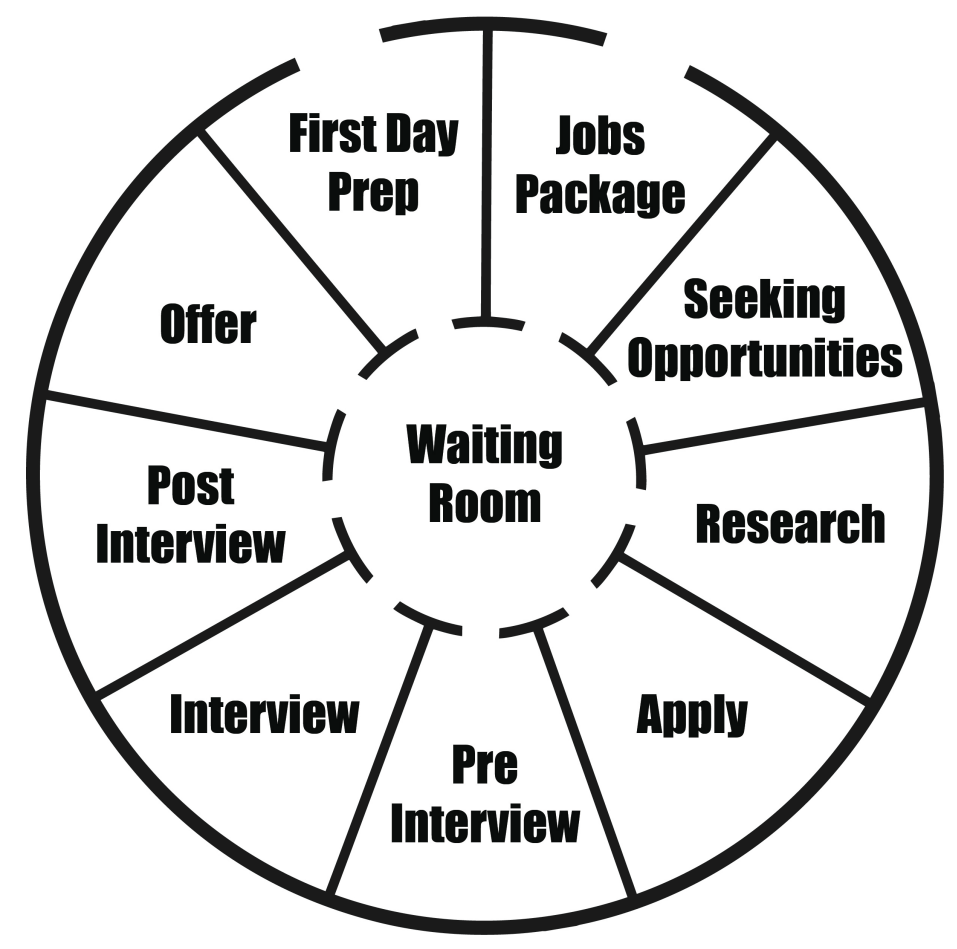

Figure 3. BELL program job search graphic

\section{Co-op Phase}

During the co-op phase, student engineers work 40-45 hours per week as engineering apprentices for a firm that employs engineers. The university program employs "facilitators" who are bachelors or masters educated engineers with engineering experience. These facilitators are the conduit between the program and the student as well as liaisons to the students' supervisors at the company. Each week, the student and facilitator have verbal conversations over Zoom or telephone. These mentor-type conversations address work experiences, learning opportunities, continuous improvement, and result in much reflection. In addition to the weekly conversations, students spend 10-12 hours per week completing school-related work. Half of the time (5-6 hours) are spent completing technical learning courses taught by the program's $\mathrm{PhD}$ professors. The other half (5-6 hours) are spent in on-line professional development workshops, writing technical design papers, and completing written reflections on the wide-variety of learning experiences taking place on the co-op placement across the professional, technical, and design domains. 
After 12 months, students return to campus for a one-week examination period where they undergo a variety of technical examinations and give multiple professional presentations in both a Ted-talk type format and traditional engineering presentation format. This exam period happens again 24 months after the EDP and immediately preceding graduation.

\section{Accreditation Details}

The BELL program is seeking accreditation as an extension to its parent program's current accreditation. The program and student learning outcomes are exactly the same as the parent project-based learning program which has twice been accredited in its ten year existence. The outcomes are extremely well aligned with ABET outcomes. The new program obviously has a different delivery modality, but the standards of student outcome achievement are the same.

\section{Focus on Co-op Placement}

This research paper focuses on the process and success for student acquisition of co-op placements. For the initial cohort, the program developers expected that the process would be straight forward. The students would sharpen their job search and interview skills through the program's jobs package, they would find and apply for positions, they would interview, and they would get/accept offers. There was an apparent shared belief among program personnel and students that it was simply a matter of numbers. There was likely a number that would be the average number of applications that would result in an offer. Early on the number 50 seemed to be reasonable. If students submitted 50 applications, they would likely get an offer. A first target of October 1st (2 months after the beginning of EDP) was set as a goal for each student to have found and applied for 50 positions. Program personnel were encouraging students throughout. They were also seeking on-line postings that students could apply to.

\section{Research Study}

\section{Research Question}

The research question focuses on the first cohort of students for the program in asking; "How do BELL program student engineers experience the attainment of their first co-op placement?"

\section{Data Collection}

The data collection section provides statistics on the effort and results of the first cohort of students. The numbers were tabulated by the facilitators in a spreadsheet with updates based on weekly meetings with the students throughout the EDP semester. Additionally, opinions and feedback were collected by one of the authors through interviews of the students and program staff at the end of the EDP semester. The research protocols applied were submitted to and approved by the Institutional Review Board, IRB. 
In Table 1, the data for the first semester co-op job search is presented for the 19 students that were continuing with the program. Data for the one student that left the program after completing the EDP semester is not included in either table.

Table 1. Cohort 1 Co-op Placement Data

\begin{tabular}{|c|c|c|c|c|}
\hline & Total & Average & Min & Max \\
\hline $\begin{array}{c}\text { Job } \\
\text { Applications }\end{array}$ & 657 & 35 & 4 & 80 \\
\hline $\begin{array}{c}\text { Follow-up } \\
\text { Connections }\end{array}$ & 109 & 5 & 1 & 16 \\
\hline $\begin{array}{c}\text { Interview } \\
\text { Requests }\end{array}$ & 34 & 2 & 1 & 4 \\
\hline $\begin{array}{c}\text { Offers } \\
\text { Accepted }\end{array}$ & 9 & $\mathrm{n} / \mathrm{a}$ & $\mathrm{n} / \mathrm{a}$ & $\mathrm{n} / \mathrm{a}$ \\
\hline $\begin{array}{c}\text { Pay Rate } \mathbf{( \$ / h r )} \\
\text { Pousing }\end{array}$ & $\mathrm{n} / \mathrm{a}$ & 20.1 & 15.0 & 23.0 \\
\hline $\begin{array}{c}\text { Hort of } 4 \\
\text { Allowance }\end{array}$ & offers & $\mathrm{n} / \mathrm{a}$ & $\mathrm{n} / \mathrm{a}$ & $\mathrm{n} / \mathrm{a}$ \\
\hline
\end{tabular}

In Table 2, the data for the first semester co-op job search is presented for the 19 students. Data is broken out between those successful in finding a co-op position by the end of the EDP semester and those still looking at that point.

Table 2. Program Cohort 1 Co-op Comparison Data

\section{At End of EDP: Co-op Achieved Still Looking}

\begin{tabular}{|c|c|c|c|c|c|c|c|c|c|}
\hline & Total & Avg & Min & Max & Total & Avg & Min & Max \\
\hline $\begin{array}{c}\text { Job } \\
\text { Applications }\end{array}$ & 295 & 33 & 4 & 66 & 362 & 36 & 12 & 80 \\
\hline $\begin{array}{c}\text { Follow-up } \\
\text { Connections }\end{array}$ & 54 & 6 & 2 & 16 & 55 & 6 & 1 & 16 \\
\hline $\begin{array}{c}\text { Interview } \\
\text { Requests }\end{array}$ & 20 & 2 & 1 & 4 & 14 & 1 & 1 & 4 \\
\hline
\end{tabular}

Interviews were done with nine BELL program students and six of the facilitators during the next to the last week of the EDP semester (this corresponds with timing of data in Tables 1 and 2 ) to gather feedback on the co-op job search process. The interviews were conducted by a researcher removed from the daily interactions with students and facilitators. One main observation stood out from the interviews; the students that had a co-op placement had obtained them through personal network connections or job fairs. The main themes that emerged from the experience and improvement interview questions are given below for both groups. 
Main Themes of Student Experience in Co-op Attainment Process

1. Co-op Placement Process Experience Trends

- emphasis of the 50 application goal by October 1 st to get their co-op

- need to start early to reach the application goal

- need for more relational networking to create internship opportunities

- value of resume and cover letter development process and the intensive 1st months

- Comments regarding consistency/inconsistency on cover letter/resume/application strategies of facilitators.

2. Thoughts for Next group of students

- Need to broaden search area for co-op; started too narrow

- Need to tailor cover letter/resume to each opportunity

- Repeat making direct connections with employers (job fairs)

- Repeat \& Improve development of Linked-In Profile

- Reach out to potential employers in their home region before they arrive

- Focus/training on cold-calling process and how to do better

- Develop BELL program network of companies to build awareness of program

Main Themes of Facilitator Experience in Co-op Placement Process

1. Co-op Placement Process Experience Trends

- Students (overall) did not reach the target number of applications. They didn't put in enough time and effort.

- Students started too narrow in co-op opportunities they pursued in both location and type/discipline.

- "Other" work competed for student time in submitting applications

2. Thoughts for Next group of students

- Need to increase student motivation towards submitting applications

- Application process should start sooner, tracked closer, and more time spent on/dedicated to it

- Decrease homework and project work as a strong first priority to increase the priority of applications

- Stronger systematic "student by student" tracking of application process

- Students need to broaden type of placements they are pursuing

\section{Analysis}

The numbers in Tables 1 and 2 demonstrate that successfully finding a co-op position during the EDP semester is not correlated to the number of applications a student makes. Table 2 shows little variation in the statistics between the successful students and those still looking. 
Included in the interview data is the impactful observation that the successful students during the EDP semester had some form of direct interaction with the hiring company outside the standard application process. These interactions included speaking with the company at job fairs or having previously worked with/known someone within the company. This is consistent with the 2019 survey by the National Association of Colleges and Employers showing employers consider career fairs the most effective recruiting technique [13]. The interviews indicate a need to adjust the broader EDP semester schedule to drive a stronger focus on and earlier effort in the co-op application process along with greater accountability. Interviews also support students developing broader co-op search criteria in this first search; not starting too focused in geographic location or type of work.

\section{Findings and Future Steps}

The nature of this ongoing DBR study is to simultaneously provide knowledge for the design of the new program and at the same time contribute knowledge creation to the broader field of engineering education. The findings from this study inform the program for the second cohort of 50 students, which starts in August 2020, and results in the identified future steps for the program. The findings also inform the broader engineering community in regards to student attainment process in a co-op centric model and continued future steps for research.

\section{Findings}

1. The communication to the students placing over-emphasis on the quantity of applications was an improper message that had negative implications.

2. There was broad-based belief by program facilitators that the solution to the problem of students not finding jobs was to simply increase the quantity of their "cold-call" applications. The data of how students actually acquired their positions does not support this belief.

3. Successful position acquisition came through career-fair contacts and network connections from the students personal or instructor networks.

4. Students struggled with perceived inconsistent feedback from program staff, causing them to have decreased confidence in their jobs-package experience.

\section{Future steps for the program}

1. The program staff should develop an extensive network of companies willing to interview students from the program.

2. The program needs to develop an approach for expanding career-fair opportunities; virtual and in-person.

3. Research driven job search methodologies should be identified and implemented in an explicit/consistent model for students. 


\section{Future steps for the research}

1. Apply the same research method 12 months later when the program has implemented future steps and the second cohort of students has reached the same point in their EDP job search phase.

2. Apply the design based research method used in this paper to the BELL program's focus on developing a network of industry connections.

\section{References}

[1] B. Johnson, R. Ulseth, Y. Wang, “Applying Design Based Research to New Work-Integrated PBL Model (The Iron Range Engineering Bell Program)". International Research Symposium on Project Based Learning (IRSPBL), Tshingua University, China. October 2018.

[2] P. Reimann, “Design-Based Research”, In: L. Markauskaite , P. Freebody, J. Irwin (eds) Methodological Choice and Design, vol 9. Springer, Dordrecht, 37-50.

[3] A. Kolmos “Design-Based Research: A Strategy for Change in Engineering Education”, In: Christensen S., Didier C., Jamison A., Meganck M., Mitcham C., Newberry B. (eds) International Perspectives on Engineering Education. Philosophy of Engineering and Technology, vol 20. Springer, Cham. 2015.

[4] D. Andriessen, "Combining design-based research and action research to test management solutions", 7th World Congress Action Learning, Action Research and Process Management, Groningen, 22-24 August, 2007.

[5] R. Ulseth, B. Johnson, "Developing the Next Generation of Co-operative Engineering Education", Project Approaches in Engineering Education (PAEE) 2018, Brasilia, Brazil. March 2018.

[6] R. Graham, The Global State of the Art in Engineering Education. Boston, MA: MIT, 2018. [7] J. Morgan, E. Lindsay, The CSU Engineering Model. In AAEE (pp. 1-8). Australia: Australian Association of Engineering Education. 2015.

[8] B. Johnson, Study of professional competency development in a Project-Based Learning (PBL)curriculum (Ph.D.). Aalborg University Press, Aalborg, Denmark. 2016.

[9] American Association of Community Colleges (AACC). Community College Fast Facts. https://www.aacc.nche.edu/research-trends/fast-facts/. Accessed 31 January, 2020.

[10] A. Kolmos, F. Fink, L. Krogh, The Aalborg PBL Model. Aalborg University Press. 2004. [11] R. Ulseth, Self-directed learning in PBL (Ph.D.). Aalborg University Press, Aalborg, Denmark. 2016. 
[12] B. Johnson, R. Ulseth, "Professional Competency Development in a PBL Curriculum", International Research Symposium on Project Based Learning, 2015.

[13] NACE Staff, "The Most Used, Most Effective Methods for Recruiting Interns, Co-ops," https://www.naceweb.org/talent-acquisition/internships/the-most-used-most-effective-methodsfor-recruiting-interns-co-ops/, 2019, (accessed March 2020). 